\title{
Climate Change Impact on Hydrological Extremes: Preliminary Results from the Polish-Norwegian Project
}

\author{
Renata J. ROMANOWICZ ${ }^{1}$, Ewa BOGDANOWICZ ${ }^{1}$, Sisay E. DEBELE ${ }^{1}$, \\ Joanna DOROSZKIEWICZ ${ }^{1}$, Hege HISDAL ${ }^{2}$, Deborah LAWRENCE ${ }^{2}$, \\ Hadush K. MERESA ${ }^{1}$, Jarosław J. NAPIÓRKOWSKI ${ }^{1}$, Marzena OSUCH ${ }^{1}$, \\ Witold G. STRUPCZEWSKI ${ }^{1}$, Donna WILSON ${ }^{2}$, and Wai Kwok WONG ${ }^{2}$ \\ ${ }^{1}$ Institute of Geophysics, Polish Academy of Sciences, Warszawa, Poland; \\ e-mail: romanowicz@igf.edu.pl \\ ${ }^{2}$ Norwegian Water Resources and Energy Directorate, Oslo, Norway
}

\begin{abstract}
This paper presents the background, objectives, and preliminary outcomes from the first year of activities of the Polish-Norwegian project CHIHE (Climate Change Impact on Hydrological Extremes). The project aims to estimate the influence of climate changes on extreme river flows (low and high) and to evaluate the impact on the frequency of occurrence of hydrological extremes. Eight "twinned" catchments in Poland and Norway serve as case studies. We present the procedures of the catchment selection applied in Norway and Poland and a database consisting of near-natural ten Polish and eight Norwegian catchments constructed for the purpose of climate impact assessment. Climate projections for selected catchments are described and compared with observations of temperature and precipitation available for the reference period. Future changes based on those projections are analysed and assessed for two periods, the near future (2021-2050) and the far-future (2071-2100). The results indicate increases in precipitation and temperature in the periods and regions studied both in Poland and Norway.
\end{abstract}

Key words: climate change, EURO-CORDEX, hydro-climatic projections, catchment selection. 


\section{INTRODUCTION}

Examination of historical observations of climate variables indicates that the evidence for anthropogenic-induced climate change is overwhelming. Following the publication of the IPCC AR3, AR4, and AR5, numerous studies at various spatial scales have considered the impact of projected changes in the climate system on hydrology and water resources. After air temperature, freshwater availability is the second most responsive environmental variable to changes in climate (IPCC 2013).

A preliminary Polish climate adaptation programme has been developed for agriculture, water management, and coastal zone management (Sadowski 2008). It is based on a selection of GCMs and IPCC sea level rise scenarios. Recently, that preliminary adaptation program has been extended to consider extreme events via the work on the adaptation to climate change by Osuch et al. (2012). This work resulted in strategic plans for adaptation to climate change in two time horizons, 2020 (SPA 2020) (IOŚ-PIB 2013) and 2070 (SPA 2070) (both documents are in Polish). There have, thus far, been no adaptation plans developed for managing risks from extreme events. Until a political decision is made on the level of protection of risk-prone areas required, it is not possible to estimate the possible costs of protection either at present or in the future. It is also not possible to estimate trends in the future costs of protection (Osuch et al. 2012).

The collaborative project "Climate Change Impact on Hydrological Extremes (CHIHE)" is part of the Research Programme of the EEA/Norway Grants Framework. The Institute of Geophysics, Polish Academy of Sciences, acts as Project Promoter and the Norwegian Water Resources and Energy Directorate acts as Project Partner. The scientific novelty of the project, amongst other things, lies in the development and adaptation of new nonstationary approaches to the analysis of changes in quantiles of hydrological extremes on a catchment scale (floods and droughts) for past events and future climate scenarios.

The project aims are:

- to investigate the effect of climate change on extreme flows (floods and droughts) in selected twinned catchments in Poland and Norway;

a to set up a preliminary benchmark dataset for Poland;

$\square$ to assess the uncertainty related to climate scenarios and hydrological modelling of observed and simulated extreme events and their basin characteristics;

$\square$ to develop and apply in practice non-stationary frequency analysis tools for high and low flow extreme events;

$\checkmark$ to evaluate the impact of climate changes on the frequency of hydrological extremes; 
- to prepare and evaluate the adaptation strategies to changes in characteristics of extreme events in Poland and Norway, with a focus on high flow events.

The development of an adaptation strategy to projected climate change impacts on high flow extremes, and a foundation for the future collaboration on the adaptation to low flow events taking into account the uncertainty of the projections are important project deliverables.

In this paper we present some results that cover the first year of the project. Namely, in Section 2 we present the methodology developed for the selection of catchments suitable for the analysis of climate change impact on extreme events under different geographic and climatic conditions in Poland and Norway, which was a task in the first work package. We also describe the selected catchments forming a database of near-natural catchments, the so-called Reference Hydrologic Networks (RHN), suitable for climate impact comparative studies. It is important to note that the selected 10 Polish catchments represent the first such database in Poland.

Secondly, in Section 3 we present an analysis of climate model projections obtained from the EURO-CORDEX initiative (Jacob et al. 2014, Kotlarski et al. 2014) which has developed future climate projections for the 21 st century. In the project, projections from the ENSEMBLE project (van der Linden and Mitchell 2009) were also used (e.g., Osuch et al. 2015). However, this is the first time that the EURO-CORDEX data have been applied in Poland.

In Section 4 we present a comparison of simulated and observed time series in the reference period 1971-2000. Section 5 describes future projections of air temperature and precipitation obtained from seven GCM/RCM models with the RCP4.5 emission scenario as an example. We thus present results of an analysis of precipitation and temperature projections in three periods: reference period (1971-2000), near future period (2021-2050), and far future period (2071-2100). Conclusions from the first year of studies in the CHIHE project and further plans are given in Section 6.

\section{HYDROLOGICAL EXTREMES}

\subsection{Floods}

Recently, Poland has experienced a number of catastrophic floods that have endangered people and property. In 2001-2010 losses related to flooding in the Upper Vistula catchment were over 14 billion PLN. Since 1990, 259 significant floods have been observed in Central Europe, of which 165 occurred after 2000 (Kundzewicz et al. 2005). This increase may be due to better information exchange and changes in land use (e.g., urbanization). Nonsequitur, it is projected that global warming will cause an increased fre- 
quency of extreme events in Europe. In addition, due to the projected decrease of snowfall and following a decrease in the risk of spring floods, the character and timing of the floods are expected to change. Even though there is no evidence of a direct relationship between the increased frequency of extreme events and climate change, the observed positive trend indicates an increased probability of urban flooding and flash floods. Moreover, changes in land use, such as urbanization, a decrease of natural retention and poor water management may strongly influence the number of extreme (flood and drought) events.

Norway has experienced a number of large floods. The most costly flood occurred in June 1995, with a total loss of 1.8 billion NOK. This flood was caused by melting snow in both the mountains and lower lying areas, combined with heavy rainfall. The total losses caused by natural disasters exceeded 2.3 billion NOK in 2011, a new record for a single year. Thirty-nine flood events occurred in Norway in that year. The years 2012 to 2015 have also had a large number of flood events, some with very high losses.

According to IPCC (2013), simulation results for the year 2050 indicate decreasing trends for river discharges and soil moisture in the summerautumn periods and a shift in the flood season from March-April to JanuaryFebruary, due to earlier snowmelt. The influence of climate change on extreme flows must be distinguished from human-induced changes in order to prepare adaptation tools for the future. The adaptation of water management to an uncertain future requires a comprehensive study of the current state and future predictions of the number, severity and frequency of extreme events. Wilson et al. (2010) examined trends in flood magnitude and timing, summer drought duration and deficit volume in the Nordic countries for the periods 1920-2005, 1941-2005, and 1965-2005. A pan-Nordic dataset of 151 stream flow records was analysed by applying the Mann-Kendall test to detect spatial and temporal changes in floods and drought. A rough differentiation of the flood generation mechanism was achieved by considering spring and autumn floods separately. The period analysed and the selection of stations influenced the regional patterns. However, a signal towards earlier spring floods and more severe droughts in southern and eastern Norway was evident in all three periods. No consistent trends were found in flood magnitudes. A qualitative comparison of the findings with available projections for daily stream flow under a future climate for the region indicates that earlier snowmelt floods are generally consistent with expected future changes. Hence, the projected changes in floods which are a consequence of increased temperatures are reflected in the observed trends, whereas changes anticipated due to increases in precipitation are not. Wong et al. (2011) found that despite small changes in future meteorological drought characteristics, an increase in hydrological drought can be expected in the future in the south- 
ernmost and northernmost parts of Norway. These findings partly show the same signal as the trends found by Wilson et al. (2010).

Changes in hydrological processes, including flooding, under a future climate in Norway have been investigated by Beldring et al. (2008), Lawrence and Haddeland (2011), and Lawrence and Hisdal (2011). The results indicate large regional differences in the impact of climate change on flooding. Areas which are currently dominated by autumn and winter floods derived primarily from heavy rainfall are expected to experience moderate to large increases in flood magnitudes under a future climate. This includes western and parts of northern Norway, and the entire coastal region. On the other hand, large river basins in which spring snowmelt dominates peak flows, as in the inland areas of southern and northern Norway, are projected to have a decreased flood magnitude. This is due to a decrease in winter snow storage, leading to a reduction in peak flows. Flood peaks in such catchments are also projected to occur earlier in the season. These projected changes in flood hazard are in good agreement with similar studies in Sweden (Bergström et al. 2012), in Finland (Veijalainen et al. 2010), and in the Baltic region (Kriaučiūnienè et al. 2008).

In Poland studies on possible scale of changes in climatic processes caused by anthropogenic forcing and in the light of the need for an adaptation strategy for water resources strategy in an uncertain environment were initiated in the 1990s by Prof. Z. Kaczmarek (Kaczmarek et al. 1996, Kaczmarek and Napiórkowski 1996). In particular, Kaczmarek (2003) examined the role of climatic and hydrological variability in assessing the cumulative risk of flood events. In that study, flood-risk estimation is combined with a frequency analysis of extreme hydrological phenomena to evaluate flood-induced damages. If, however, the process is non-stationary, the risk of flood damage may also depend significantly on the variability of hydrological processes. In that study, it was found that spatial variation was larger than seasonal variability, which may indicate changes related to land use and water management. Kundzewicz et al. (2013) presented a comprehensive review of flood risk assessments in Europe. Romanowicz and Osuch (2011) applied a number of different statistical and model-based tools to separate the influence of climate and land use changes on flows in the Upper Narew catchment. The results showed that changes related to water management were suppressing any other impacts on flow magnitude.

The potential effects of long-term environmental changes on flood risk, including climate change, should be considered in conjunction with both preliminary flood risk mapping and the development of flood risk management plans. Therefore, assessments regarding likely climate change impacts on flood frequency must be developed from global and regional climate projections (IPCC 2007) so that this future effect can be considered. In Norway, 
the hydrological projections for changes in flooding under a future climate presented in Lawrence and Hisdal (2011) have been used to develop regional guidance for taking account of climate change in flood risk management. Three categories for changes in flood discharge have been recommended in practise: $0,20 \%$, and $40 \%$. It is advised that flood hazard maps illustrate or otherwise indicate patterns of flood inundation both in today's and under a future climate, based on these assessed changes (e.g., Edvardsen and Roald 2012).

\subsection{Droughts}

Droughts have a substantial impact on ecosystems and the agriculture of the affected region, but also for the country/region's economy in general. Obviously, the cause and effects of floods and droughts could not be more different; surprisingly, however, many statistical methods for their description and analysis are quite similar. Droughts, as floods, can be characterised by their severity, duration, intensity, inter-arrival time, and other direct and indirect parameters. Such a multi-parameter character of the phenomena induces modellers to concentrate on one dominating parameter of the flood (important for the sake of the project's purpose) or to apply multivariate methods commonly used in Flood Frequency Analysis (FFA) and Flood Risk Analysis (FRA). Among the many possible probabilistic methods for drought analysis (see, e.g., Mishra and Singh 2011) the estimation of return periods for time-dependent drought parameters and univariate or bivariate drought analysis will be the main subject of investigation in our project.

An example of a univariate technique is the fitting of the sample frequency distribution of drought characteristics using univariate probability distribution functions (e.g., Shiau and Shen 2001, Cancelliere and Salas 2004). However, analyses of the drought return period (and quantiles) and frequency of low flow occurrence require long data series. The availability of such series is even less commonly available than similar series for peak flows, due to the fact that droughts are infrequent but of long duration. Thus, long time series are required to capture a sufficient distribution of events for analyses. To meet the requirements of this project, a scrutiny of drought frequency should be accompanied by an analysis of its duration (Fernández and Salas 1999a,b; Chung and Salas 2000). This directs us towards either univariate models in which the duration of the flow below an assumed threshold is a random variable (Shiau and Shen 2001, Strupczewski et al. 2012) or bivariate (frequency-duration) statistics with the help of copulas. The former methodology was successfully applied by Strupczewski et al. (2012) for duration-depth-frequency modelling developed for flood analysis, but can easily be applied to drought modelling and extended to nonstationary conditions under climate change (Hisdal and Tallaksen 2003). 
The latter techniques, based on univariate marginal distributions combined with copula functions, have recently become extremely popular among hydrologists (e.g., Favre et al. 2004, Salvadori and De Michele 2004) and seem to be a cure-all for every aspect of the hydrology of extremes. Therefore, we plan to verify the limits of this methodology within the context of its applicability to drought modelling and to evaluate whether it is possible to use copulas to join several very different components into one useful model of droughts. To the best of our knowledge the application of copulas in hydrology is a novel approach in Poland (Strupczewski et al. 2015).

\section{CATCHMENT SELECTION}

\subsection{Criteria for catchment selection}

The CHIHE study is based on the analysis of a set of study catchments, both for Poland and Norway. The basis for selecting catchments suitable for the analysis of the influence of climate forcing on extreme flows (both low and high flows) applied in this study follows the rules recommended for the development of Reference Hydrologic Networks (RHN). Many countries have invested in a RHN database of streamflow gauging stations that are maintained and operated with the intention of observing how the hydrology of watersheds responds to variations in climate (Stahl et al. 2010, Monk et al. 2011, Fleig et al. 2013). In general, streamflow and climate records from reference hydro-climate networks are used to represent near-natural river flow regimes from catchments with varying hydro-climate characteristics, usually assumed to be representative of a broad range of regions. The networks provide time series records suitable for investigating the predominant climate and catchment processes that govern changes in regional hydrology. Data from such "reference" networks are of fundamental importance for detection and attribution studies and for the validation of large-scale climate and hydrological models (Slack and Landwehr 1992, Mishra and Coulibaly 2010, Raje and Mujumdar 2010, Hannah et al. 2011).

The main criteria that should be fulfilled by the catchments belonging to RHN are (Whitfield et al. 2012):

口 Degree of basin development. Ideally, catchments should be pristine or at least have stable land-use conditions; catchments have an urban area $<10 \%$;

- Absence of significant regulations, diversions, or water use. A catchment is considered natural only if there is no substantial control structure upstream or water extraction within the basin, or diversions between basins. When regulation is present in a basin, some gauging stations may be appropriate for analyzing high flows and average flows, but not, for example, low flows; 
- Record length. Any RHN station must have a minimum record length of 20 years. This length ensures that underrepresented climatic or geographic areas, which are characterized by minimal data availability, are also included. However, record lengths should also be as long as possible to allow decadal variability to be distinguished from long-term trends; in this project we require a minimum of 30 years of record;

- Active data collection. A station is included in the network if it is currently active and is expected to continue operation until it achieves the desired record length;

口 Data accuracy. Only stations with what is considered good quality data are included in the network, i.e., stations with reliable rating curves and with records tested for homogeneity. Stations with poorly or unquantified factors, such as changes in the river bed profile winter ice and spring ice jams or other difficult measuring conditions, should not be included;

- Adequate metadata. Adequate metadata should be available to support the above five conditions.

These criteria should be supported by additional analysis of catchment geomorphology and an analysis of the hydrological regime of the catchment (Hannaford and Marsh 2006, Marsh 2010, Thorne et al. 2010).

In heavily populated parts of Europe, with a long history of human disturbance, there are few pristine catchments, so some degree of disturbance must be tolerated. In the United Kingdom, for example, catchments where the net impact of abstractions and discharges are considered to be within $10 \%$ of the natural flow, flows at or in excess of the Q95 are deemed suitable for representative basin status (Hannaford and Marsh 2008). Polish catchments are characterized by a high degree of agricultural and forest land use. It may be appropriate to use these catchments in our database if agricultural practices have remained constant during the period of interest. In Norway, many areas are considered to have pristine conditions; however, changes in grazing patterns over the past century have contributed to afforestation in some areas. This effect is currently unquantified, but again, must be tolerated within the context of this study until more information is available.

The applied selection procedure can be illustrated using Norwegian and Polish catchments. The Norwegian stations both belong to the National Reference Database (Fleig et al. 2013) and have had their modelling capabilities tested (Lawrence et al. 2009). In the case of Polish catchments the calibration and validation of rainfall-runoff models have to be performed. A conceptual rainfall-runoff HBV model (Bergström et al. 2001) was chosen for that purpose. Results of calibration and validation procedures are used as additional criteria for catchment selection. Namely, only catchments with good calibration/validation results are selected for further analysis, as bad model 
performance indicates an unresolved problem in modelling a rainfall-runoff process in the catchment (Romanowicz et al. 2013). Additional selection criteria are linked to specific project aims, i.e., a comparison of Polish and Norwegian catchments from the point of impact of climate change on hydrological extremes. Therefore, the selected catchments were required to: (i) provide a good spatial coverage across the country; (ii) provide representative stations of the different flood and summer drought characteristics, which can be used for the pairing of Norwegian and Polish stations; and (iii) to have catchment characteristics that aid pairing of the Norwegian and Polish stations.

\subsection{Evaluation of observation data sets}

In Poland a set of 41 catchments was available for use within the project. Precipitation data were compiled from 79 climate stations and 58 synoptic stations across the country. Temperature data from 79 synoptic and climatic stations were also available. The synoptic data cover the full time period 1951-2010, but among climatic stations only about $50 \%$ have a full data range. Out of all the available stations, 39 gauged Polish stations were selected to provide hydrological information. On average, the length of all records spans the period 1950 to 2010. All data sets have daily data. Thiessen polygons were applied to derive precipitation data specific to each catchment. Land use data for 1990, 2000, and 2006 were collected from the EEA website (EEA 2014) and used to assess land use change.

The Norwegian gauging stations considered for use within this project have been previously scrutinized for inclusion in the Norwegian Benchmark dataset for climate change studies (Fleig et al. 2013). That dataset consists of 138 long term records suitable for both high and low flow studies, together with information on the characterizes of the catchments.

The availability of precipitation and temperature data was not an issue for the Norwegian gauging station selection since catchment average values derived from $1 \times 1 \mathrm{~km}^{2}$ gridded observation based datasets are routinely used to calibrated and run the HBV catchment models, and will therefore be used in this study. These gridded datasets are available for Norway for the period 1958 to present and are presented at www.senorge.no, with the station data having undergone various quality checks before deriving the gridded series (Tveito et al. 2005). The gridded precipitation dataset was also the subject of a trend analysis of moderate to strong precipitation events across Norway in Dyrrdal et al. (2012). However, there are issues with using gridded datasets for trend analyses since different stations used to derive gridded temperature and precipitation values during a period could result in the false identification of a trend. In addition, the Meteorological Office in Norway (MET) 
does not use homogeneous time series as a basis for their gridded datasets. Preliminary analyses have shown that changes in the station network and the addition of stations have a greater impact on the quality and homogeneity of the grids locally than the use of homogeneous or non-homogeneous time series. Nevertheless, similar problems are likely to arise deriving catchment average rainfall using alternative procedures, such as Thiessen polygons. In addition, the use of meteorological data from a single station, often located outside a catchment, can be unrepresentative of the true catchment average values.

Wilson et al. (2010) undertook a trend analysis of a pan-Nordic dataset of 151 pristine streamflow records, which includes many of the Norwegian stations available for use in this study. In addition to standard quality control procedures at the national hydrological institutions, a visual inspection of the dataset was undertaken prior to the analyses.

\subsection{Hydrological regimes}

\section{Flood regime}

In Poland 41 catchments were classified into three types of flood regime categories: (i) snowmelt, (ii) rainfall, and (iii) mixed, based on their seasonal event number contribution to the total number of annual events in each station. Where the contribution of winter season events is higher than $66.67 \%$ to the annual, the flood regime is classified as a snowmelt driven regime, and if the summer season contributes more than $66.67 \%$ to annual flood, it is defined as a rainfall driven regime. The mixed regime occurs in between. We used two types of threshold values: (i) daily maximum flow of $80-90 \%$ probability as a threshold to count the number of events in a specific catchment; (ii) rainfall/snow melt regime - contribution greater than $66.7 \%$ of flow is directly caused by rainfall/snow melt, respectively; mixed regime - if the percentage contribution is in between those probability ranges.

In Norway all 138 catchments have been classified on the basis of their flood regime into the following types: (i) snowmelt, (ii) rainfall, and (iii) mixed, based on the percentage of years that a flood is caused by either snowmelt, rainfall or a contribution of both factors. Where the percentage of years that the annual maximum flood is caused by either snowmelt or rainfall is greater than $2 / 3$, the respective mechanism is given as the characteristics of the flood regime. Where neither snowmelt nor rainfall alone accounts for more than $2 / 3$ of the annual maxima flood events at a station, the flood regime is classified as mixed. As an illustration, the classifications of Polish and Norwegian catchments for the final selected catchments are given in Figs. $1 \mathrm{a}$ and $1 \mathrm{~b}$, respectively. 


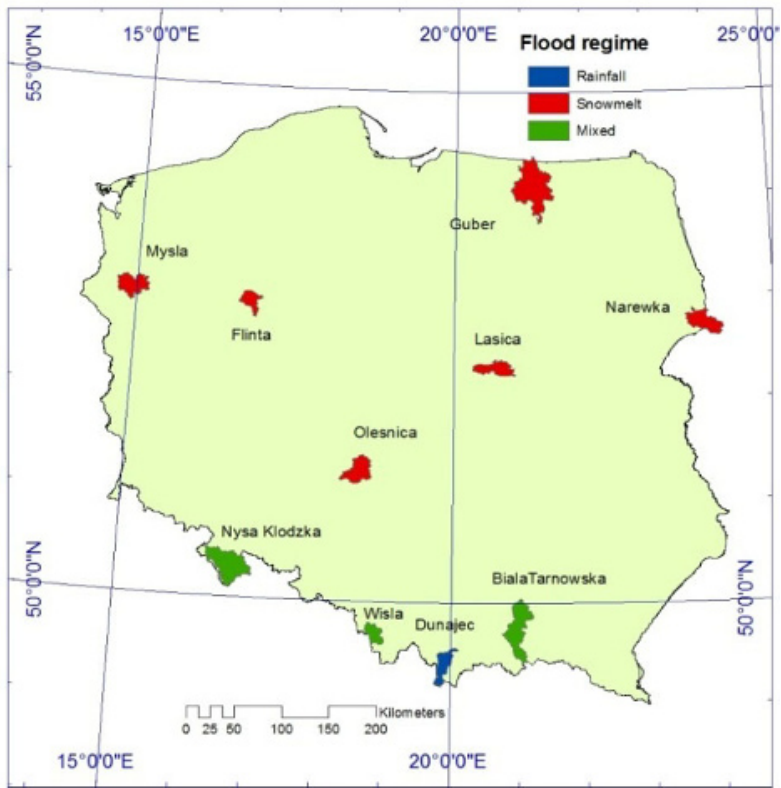

Fig. 1a. Flood regime classification in selected Polish catchments.

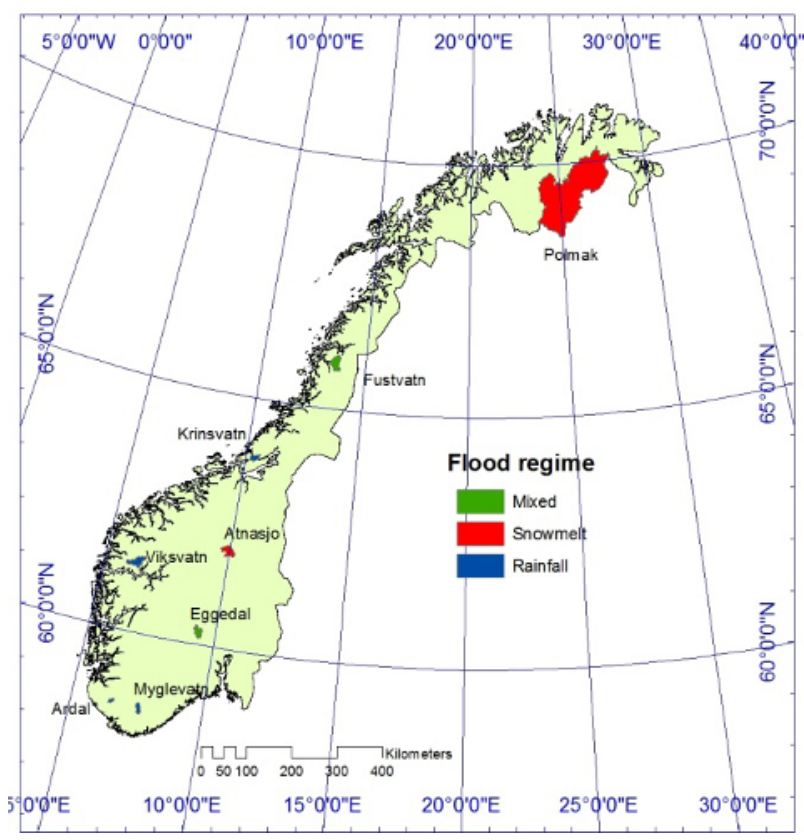

Fig. 1b. Flood regime classification for the Norwegian catchments based on the percentage of the events comprising the annual maximum series which are driven by $>60 \%$ rainfall (versus snowmelt) input. 


\subsection{Homogeneity testing}

Given that floods and droughts are the focus of this study, the following parameters have been selected to establish the homogeneity of the data series at each station and to assess their suitability for use in this project:

a mean daily flow values,

a median annual flow,

a annual total (the sum of daily streamflow over a year),

a annual maxima daily peak flow,

口 annual Q5 (flow with exceedance probability 0.05 ),

- annual summer minima, with a 7-day moving average (see definition of summer below),

口 annual summer Q80 (flow with exceedance probability 0.8 ), with 7-day moving average.

Homogeneity testing has been undertaken for each of the parameters detailed above. A data series is homogeneous if it represents the natural discharge from a catchment (Astrup 2000). However, sudden inhomogeneity can occur due to, for example, changes in instrumentation, observation method, regulation, changes in gauge location and/or surrounding conditions. This study does not consider gradual changes or trends in the identification of inhomogeneity in each series, since this is the focus of a later assessment. Some inhomogeneity may affect the whole data series, whilst others may affect only high or low water levels. There are various homogeneity tests available, but it can be difficult to specify the actual date of an inhomogeneity, and it is therefore beneficial to compare the results of several tests in order to specify more accurately the date of a break (Astrup 2000). Figure 2 illustrates the homogeneity testing procedure used in this study, with further details about each of the tests given below:

a Visual inspection - visual inspection of a time series plot is arguably the most effective method for validating streamflow data (Gustard and Demuth 2009), and is used to identify individual potentially erroneous values or jumps in a data series;

- Bayesian analysis - this procedure is used to infer the probability that a data series is homogeneous, as well as identifying the probability that a jump exists within a dataset. This analysis is based on both prior understanding of the probability $(P)$ of homogeneity within a data series (i.e., before the data are available) and the actual data. For all of the homogeneity assessments in this study, the prior probability for homogeneity has been set to $50 \%$ for annual values, based on user experience for the Norwegian data series (Reitan and Petersen-Øverleir 2005). In determining whether a series is homogeneous, a threshold of homogeneity was taken to be $50 \%$. Where $P>50 \%$, this is taken as evidence of homogeneity, and 


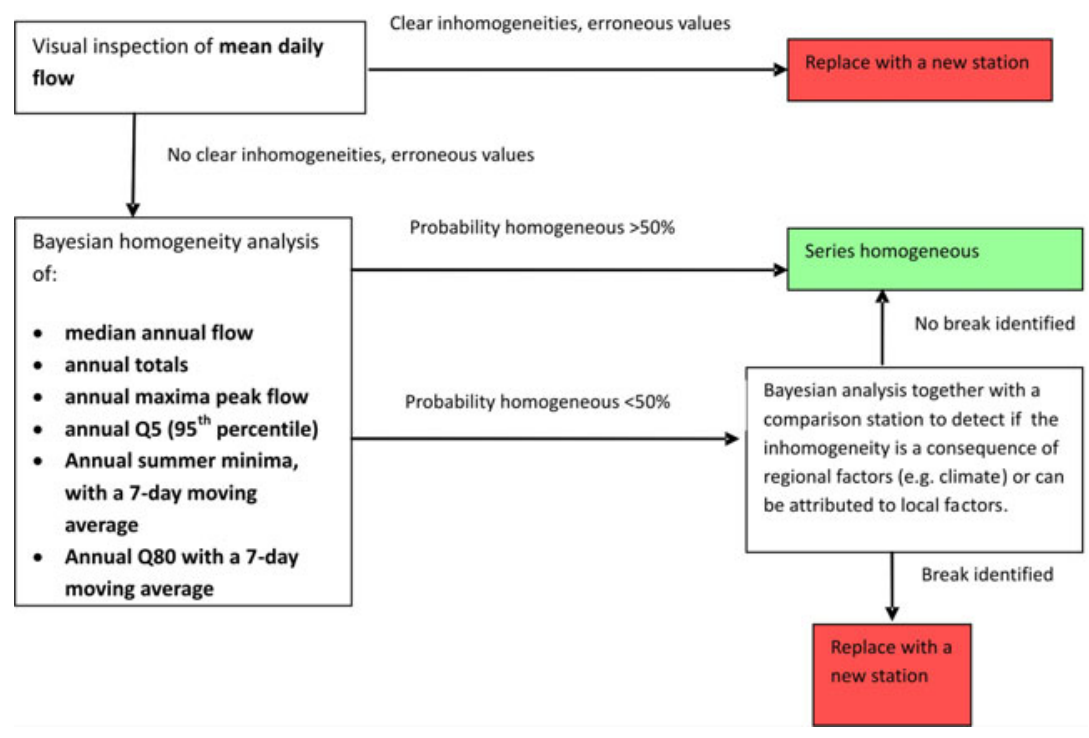

Fig. 2. Flow diagram illustrating the procedure undertaken to establish the homogeneity of the flow record at each gauging station.

where $P<50 \%$ this is taken as evidence of inhomogeneity. The strength of the evidence depends on how much $P$ increases or decreases. For these analyses, NVE's in-house Hydra II software "Check Homogeneity" (Reitan and Petersen-Øverleir 2005) has been used.

a Bayesian analysis using a comparison station - this procedure seeks to detect a break in a station's data series, identified by comparison with the series from another nearby station. The aim of this homogeneity test differs from the Bayesian analysis detailed above, since it seeks to detect whether a jump in a series can be explained by regional climate variations which affect several stations, rather than an inhomogeneity being caused by changes in a local parameter at a station (e.g., the gauging station being moved). This is undertaken by analyzing a new series which is the ratio between the subject series and the comparison series:

New series $=$ subject series $/$ comparison series

If homogeneities are influenced by regional factors, rather than local changes at a station, any jump should be detectable in both station series. A sudden jump in the new series indicates a possible inhomogeneity in only one of the series, but in which series the inhomogeneity lies cannot be determined based on this test alone. This analysis procedure relies on a single station or group of nearby stations with similar climate and catchment characteristics that can be used to help establish the homogeneity of 
the selected station. Different parameters can also be compared (e.g., precipitation and streamflow). However, if it is extremely wet or dry, two catchments may respond differently in comparison to a normal year.

\section{Hydrological modeling}

The HBV model was applied to rainfall-runoff modelling in both Norway and Poland. As mentioned in Section 3.1, the HBV model has already been tested for the Norwegian catchments (Lawrence et al. 2009). However, the HBV model had to be calibrated and validated for all selected Polish catchments.

As an input to the HBV models, precipitation, temperature, and streamflow data from 39 catchments were prepared. Observations for the period 1971-2000 were applied during the calibration stage, and the period 20012010 was used for validation (Table 1).

Table 1

Results of calibration and validation (the Nash-Sutcliffe coefficient) of ten selected catchments in Poland

\begin{tabular}{|c|l|l|c|c|}
\hline \multirow{2}{*}{$\begin{array}{c}\text { Station } \\
\text { number }\end{array}$} & \multicolumn{1}{|c|}{ Gauging station } & \multicolumn{1}{|c|}{ River } & $1971-2000$ & 2001-2010 \\
\cline { 3 - 5 } & & Calibration & Verification \\
\hline 1 & Koszyce Wielkie & Biała Tarnowska & 0.7874 & 0.7558 \\
2 & Nowy Targ Kowaniec & Dunajec & 0.7678 & 0.7990 \\
3 & Skoczów & Wisła & 0.6556 & 0.7541 \\
4 & Kłodzko & Nysa Kłodzka & 0.6412 & 0.6039 \\
5 & Niechmirów & Oleśnica & 0.7166 & 0.5309 \\
6 & Władysławów & Lasica & 0.6030 & 0.5345 \\
7 & Narewka & Narewka & 0.6876 & 0.5597 \\
8 & Prosna & Guber & 0.5043 & 0.5270 \\
9 & Ryczywół & Flinta & 0.7001 & 0.5911 \\
10 & Myślibórz & Myśla & 0.7074 & 0.4989 \\
\hline
\end{tabular}

The HBV model parameters were optimized using the DEGL (Differential Evolution with Global and Local neighbors) method (Storn and Price 1997). As an objective function the Nash-Sutcliffe coefficient was used (Nash and Sutcliff 1970). All Polish catchments marked in Fig. 1 were calibrated and validated during the selection procedure.

\subsection{Final catchment selection}

The selected study areas include ten catchments in Poland and eight catchments in Norway (Figs. 1a and 1b). These catchments have diverse hydroclimatic conditions. The watershed area ranges from 77.25 to $14161 \mathrm{~km}^{2}$. 
The catchments are covered mostly by forest and are near-natural. The flood regimes of all selected catchments are driven either by rainfall and/or snowmelt (Table 2).

Table 2

List of selected catchments in Poland and Norway for streamflow and precipitation variables

\begin{tabular}{|c|c|c|c|c|c|c|}
\hline Country & Station & Catchment & $\begin{array}{c}\text { Area } \\
{\left[\mathrm{km}^{2}\right]}\end{array}$ & $\begin{array}{l}\text { Flood } \\
\text { regime }\end{array}$ & $\begin{array}{c}P M \\
{[\mathrm{~mm}]}\end{array}$ & $\underset{\left[\mathrm{m}^{3} / \mathrm{s}\right]}{Q M}$ \\
\hline \multirow{10}{*}{ Poland } & 1 & Biała Tarnowska & 966.9 & Mixed & 2.1 & 9.0 \\
\hline & 2 & Dunajec & 681.1 & Rainfall & 3.1 & 14.5 \\
\hline & 3 & Wisła & 296.5 & Mixed & 2.6 & 6.1 \\
\hline & 4 & Nysa Kłodzka & 1061.5 & Mixed & 2.1 & 12.9 \\
\hline & 5 & Oleśnica & 583.5 & Snow melt & 1.6 & 2.5 \\
\hline & 6 & Łasica & 629.3 & Snow melt & 1.5 & 1.1 \\
\hline & 7 & Narewka & 635.3 & Snow melt & 1.8 & 3.0 \\
\hline & 8 & Guber & 1554.5 & Snow melt & 1.6 & 8.5 \\
\hline & 9 & Flinta & 813.4 & Snow melt & 1.5 & 0.7 \\
\hline & 10 & Myśla & 586.9 & Snow melt & 1.5 & 1.3 \\
\hline \multirow{8}{*}{ Norway } & 1 & Polmak & 14161.4 & Snow melt & 1.4 & 179.2 \\
\hline & 2 & Årdal & 77.25 & Rainfall & 9.3 & 12.5 \\
\hline & 3 & Fustvatn & 525.69 & Mixed & 6.6 & 32.7 \\
\hline & 4 & Krinsvatn & 206.61 & Rainfall & 6.8 & 12.6 \\
\hline & 5 & Atnasjø & 463.2 & Snow melt & 2.3 & 10.2 \\
\hline & 6 & Myglevatn & 182.2 & Rainfall & 6.1 & 8.0 \\
\hline & 7 & Viksavtn & 508.13 & Rainfall & 10.5 & 44.8 \\
\hline & 8 & Eggedal & 309.77 & Mixed & 3.8 & 6.9 \\
\hline
\end{tabular}

Explanations: $Q M$ is an average value of streamflow daily, $P M$ is an average value of precipitation daily.

The temporal patterns of observed annual sums of precipitation and annual mean air temperature in ten Polish catchments for the period 1970-2000 are shown in Fig. 3. The catchments are located in varying hydro-climatic conditions of Poland: Nysa Kłodzka, Wisła, Dunajec, and Biała Tarnowska are in the highlands (south); Myśla and Flinta are in the western part; Łasica and Oleśnica are in the central; Narewka and Guber are located in the north and east part of the country. There is a large difference in precipitation amounts between the northern, southern, and western parts of Poland. Precipitation time series do not show clear trends in any of the catchments. The lowest precipitation is observed in Myśla, Flinta, and Oleśnica, situated in north-west Poland. 


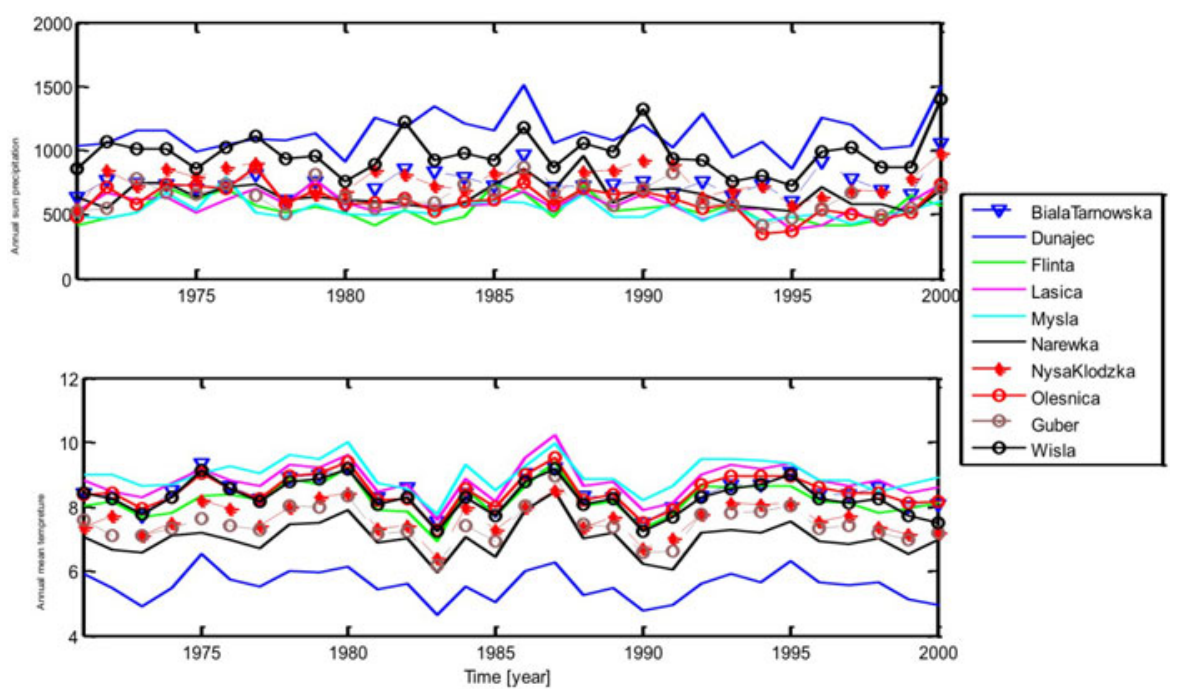

Fig. 3. Annual sums of precipitation [mm] (upper panel) and annual mean air temperature $\left[{ }^{\circ} \mathrm{C}\right]$ (lower panel), over the period 1971-2000 in the selected ten catchments in Poland.

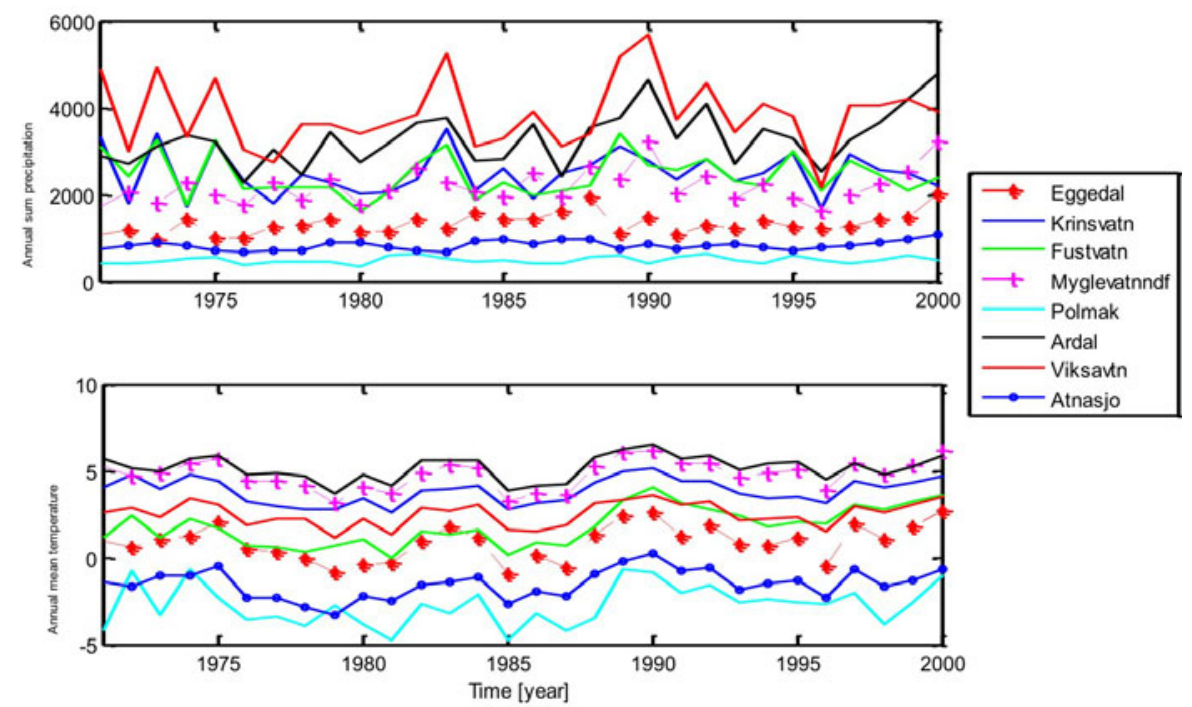

Fig. 4. Annual sum of precipitation [mm] (upper panel) and annual mean air temperature $\left[{ }^{\circ} \mathrm{C}\right]$ (lower panel), over the period 1971-2000 in the selected eight catchments in Norway.

The annual sums of precipitation and annual mean air temperature in the eight catchments from Norway are presented in Fig. 4. Amongst the Norwegian catchments, Myglevatn and Årdal are located not far from the southern 
and southwestern coast of Norway, respectively. Viksvatn and Krinsvatn are located on the western coast of southern and middle Norway. All of these four catchments have relatively wet and warm climate conditions, by Norwegian standards. Fustvatn is also influenced by coastal conditions, with high precipitation volumes, although it is farther north and is therefore somewhat cooler than the other four. The remaining catchments, Eggedal, Atnasjø and Polmak, are all characterized by inland climate conditions with cold winters leading to lower annual temperatures and overall drier conditions throughout much of the year. The most northern catchment, Polmak, is most pronounced in this regard.

\section{CLIMATE PROJECTIONS}

To assess the impact of climate change on flood and drought conditions in Poland, we will use the newest source of climate projections available from the EURO-CORDEX initiative (Jacob et al. 2014, Kotlarski et al. 2014). The EURO-CORDEX simulations use the new Representative Concentration Pathways (RCPs) scenario products which are defined by Moss et al. (2010) and applied in the fifth IPCC Report. Four emission scenarios: RCP2.6, RCP4.5, RCP6, and RCP8.5, were created and named after a possible range of radiative forcing values in the year 2100 relative to pre-industrial values $\left(+2.6,+4.5,+6.0\right.$, and $+8.5 \mathrm{~W} / \mathrm{m}^{2}$, respectively) (Moss et al. 2010). RCP2.6 is a very low emission scenario requiring a considerable reduction from 2020 , zero emissions from 2080, and removal of climate gasses from the atmosphere. This is the only scenario with a global warming of less than 2 degrees compared to 1850-1900. The RCP4.5 is an "intermediate pathway" in which radiative forcing is stabilized after 2100 (Clarke et al. 2007). The resulting global warming is estimated to be around 2.5 degrees towards the end of the century. RCP6.0 is also an intermediate pathway and very similar to RCP4.5 until the middle of the century. RCP8.5 is the highest emission scenario, also referred to as "business as usual", and implies a global warming of more than 4 degrees in 2100. According to Clarke et al. (2007), the new RCP scenarios have many advantages over the older SRES scenarios (Nakicenovic et al. 2000) in that they provide more information for understanding the climate system and carbon-cycle behaviour. The new scenarios also include more detailed information than provided by SRES: aerosol emissions, geographically explicit descriptions of land use and emissions, and detailed specification of emissions by source type (Edenhofer et al. 2010, van Vuuren et al. 2007).

The climatic variables to be used in this project have been obtained from EURO-CORDEX initiative in the form of time series of daily sums of precipitation and mean daily air temperature derived from seven different combinations of global and regional climate models: CNRM-CM5-CCLM4-8-17, 
EC-EARTH-CCLM4-8-17, EC-EARTH-HIRHAM5, EC-EARTHRACMO22E, EC-EARTH-RCA4, MPI-ESM-LR-CCLM4-8-17, and MPIESM-LR-RCA4 (Jacob et al. 2014, Kotlarski et al. 2014). The selected combination of models consists of three GCMs: EC-EARTH, MPI-ESM-LR, and CNRM-CM5 and four RCMs (Table 3). The selected available RCM/ GCMs provide projections of climatic variables up to the year 2100 at a resolution of $12.5 \mathrm{~km}$. Analyses of hydro-meteorological conditions were conducted for the whole 1971-2100 period. For purposes of comparison, three periods are used: 1971-2000, the so-called "reference" period, and two future periods: "near future" (2021-2050) and "far future" (2071-2100) period.

Table 3

List of GCM/RCM climate models applied

\begin{tabular}{|l|c|c|c|c|}
\hline GCM $\backslash$ RCM & RCA4 & HIRHAM5 & CCLM4-8-17 & RACMO22E \\
\hline EC-EARTH & $\checkmark$ & $\checkmark$ & $\checkmark$ & $\checkmark$ \\
MPI-ESM-LR & $\checkmark$ & - & $\checkmark$ & - \\
CNRM-CM5 & - & - & $\checkmark$ & - \\
\hline
\end{tabular}

The quality of climate projections of precipitation and air temperature is very important for reliable and accurate future extreme value predictions. The RCM/GCMs simulations are generally biased and cannot be used as forcing variables in flood and drought prediction at the catchment-scale without some form of prior bias correction. Several studies have been performed in which a bias correction method was applied to RCM data (e.g., Berg et al. 2012, Li et al. 2012, Teng et al. 2012, Lafon et al. 2013, Cloke et al. 2013). In this study, quantile mapping methods (e.g., Piani et al. 2010, Gudmundsson et al. 2012) have been used for each catchment to correct simulated precipitation and air temperature time series. Both empirical and distribution-based methods have been applied. The methods are based on correcting the RCM data such that the resulting distribution function better matches that of the observed during the reference period. Empirical methods use the empirical distribution function of the observed and RCM data for this purpose, whereas distribution-based methods fit a particular function (e.g., a gamma function) to both the observed data and the RCM data. Further details of these procedures can be found in Gudmundsson et al. (2012). On this basis, transformation of the quantiles of simulated time series relative to the observed series is derived, and this correction is then applied to the simulated time series. Due to problems with realistic simulations of the seasonal pattern of precipitation by the RCM models, these transformations were derived independently for each month. This can sometimes lead to problems during very dry summer months simulated by some of the RCMs, as a suffi- 
cient number of dry days are not available to develop a robust correction. The transformations derived in the reference time period are also applied to correct RCM data for the future periods, thus assuming that the corrections are invariant with respect to climate change. For correcting the bias in the air temperature series from the RCM, empirical quantile mapping was used on the residuals, after removing the difference in the air temperature between the reference and the future period. This must be done to ensure that bias correction does not remove the climate change signal for temperature.

\section{COMPARISON OF SIMULATED AND OBSERVED CLIMATE TIME SERIES IN THE REFERENCE PERIOD}

In the first step of the analysis, a comparison of the observed and simulated precipitation and air temperature time series for the reference period (19712000) was performed. Figure 5a shows a comparison of historical monthly sums of precipitation, uncorrected precipitation, and corrected precipitation in the reference period for seven climate models for two Polish catchments, Dunajec (upper panel) and Narewka (lower panel). It is seen that all uncorrected simulations overestimate monthly sums of precipitation, except for the months of June, July, and August, when precipitation sums are underestimated by two models ( $\mathrm{m} 1$ - CNRM-CM5-CCLM4-8-17 and m2 - ECEARTH-CCLM4-8-17). Differences between climate model simulations are generally large. A comparison of the uncorrected precipitation simulations with observations indicates consistency in most catchments. The worst results are obtained for the two mountainous catchments: Nysa Kłodzka and Wisła. In general, the uncorrected precipitation simulations from EUROCORDEX are significantly better than climate simulations from the ENSEMBLES project (Osuch et al. 2015). The application of bias correction by the double gamma method (Yang et al. 2010) significantly improved the simulated monthly total precipitation for the selected catchments in Poland.

A comparison of the observed and simulated monthly air temperatures in the 1971-2000 period for two studied catchments, Dunajec and Narewka, is presented in Fig. 5b. The results of comparison between uncorrected simulations (black lines) and observations (red line) indicate that most of the climate models underestimate the observed mean monthly air temperature. Only the simulations from CNRM-CM5-CCLM4-8-17 overestimate air temperature in summer months. As in the case of precipitation, the application of bias correction significantly improves air temperature simulations.

For Norway, Sorteberg et al. (2014) compared different bias correction methods for precipitation and temperature, including both Empirical Quantile Mapping and single and double gamma functions for a limited set of locations in Norway, based on the EURO-CORDEX RCM data available at that time. A range of multi-objective indices was compared to evaluate 

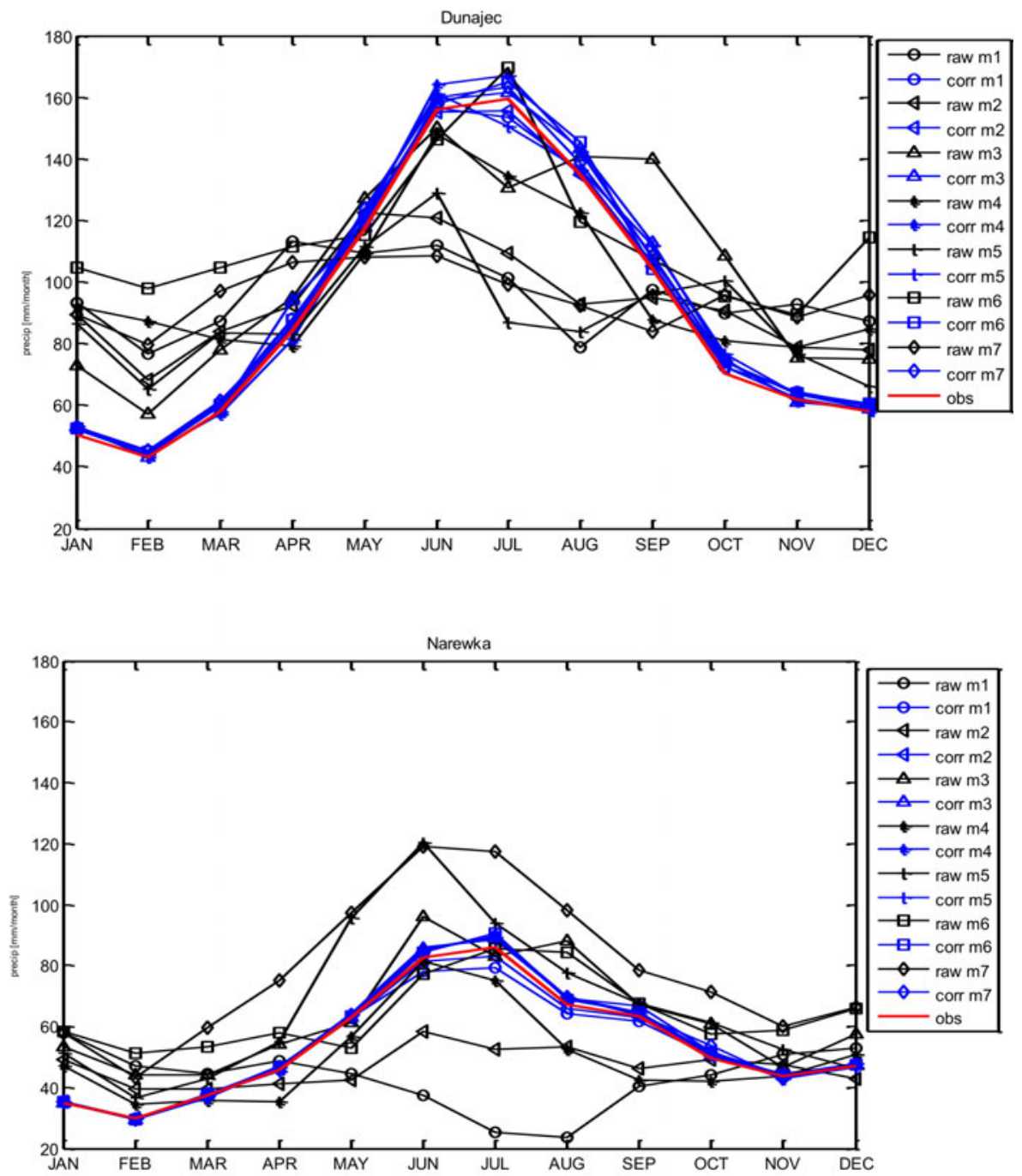

Fig. 5a. Comparison of historical monthly precipitation totals (red color), uncorrected precipitation (black color), and corrected precipitation (blue color) in the reference period (1971-2000) for seven climate models (m1 - CNRM-CM5-CCLM4-817, m2 - EC-EARTH-CCLM4-8-17, m3 - EC-EARTH-HIRHAM5, m4 - ECEARTH-RACMO22E, m5 - EC-EARTH-RCA4, m6 - MPI-ESM-LR -CCLM4-817, m7 - MPI-ESM-LR -SMHI-RCA4) for two catchments located in Poland, Dunajec (upper panel) and Narewka (lower panel). 

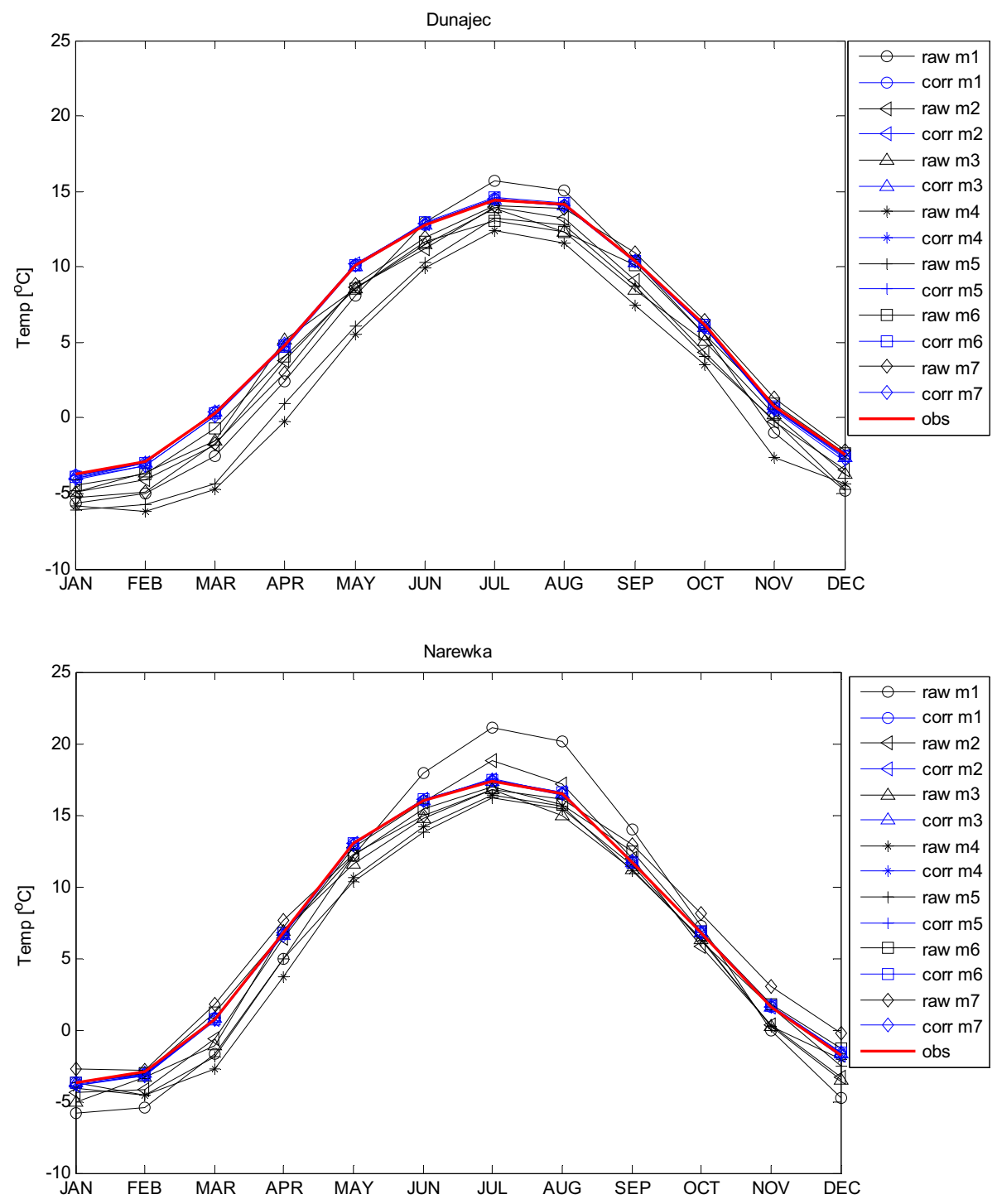

Fig. 5b. Comparison of historical monthly mean temperatures (red color) with simulated uncorrected temperatures (blue color) and corrected temperatures (black color) in the reference period (1971-2000) for seven climate models (m1 - CNRM-CM5CCLM4-8-17, m2 - EC-EARTH-CCLM4-8-17, m3 - EC-EARTH-HIRHAM5, m4 - EC-EARTH-RACMO22E, m5 - EC-EARTH-RCA4, m6 - MPI-ESM-LRCCLM4-8-17, m7 - MPI-ESM-LR -SMHI-RCA4) for two catchments located in Poland, Dunajec (upper panel) and Narewka (lower panel). 
the performance of the methods for a test period. This comparison and evaluation of the need for computational resources formed the basis for the selection of bias correction methods to be used for the $1 \times 1 \mathrm{~km}^{2}$ gridded data set. Although the study concluded that distribution-based methods can perform better, practical limitations with respect to computing time led to the use of empirical quantile mapping for national work in Norway. In this project, however, bias correction was performed relative to spatially-averaged values of precipitation and temperature for the eight Norwegian catchments, and this bias correction was performed using both empirical quantile mapping and the use of a double gamma function. In this way, direct comparisons could be made between the results for both Poland and Norway.

\section{PRECIPITATION AND TEMPERATURE CHANGES IN NEAR AND FAR FUTURE IN THE POLISH AND NORWEGIAN CATCHMENTS}

A comparison of the change in annual precipitation in three periods: 19712000, 2021-2050, and 2071-2100, in ten Polish catchments is presented in
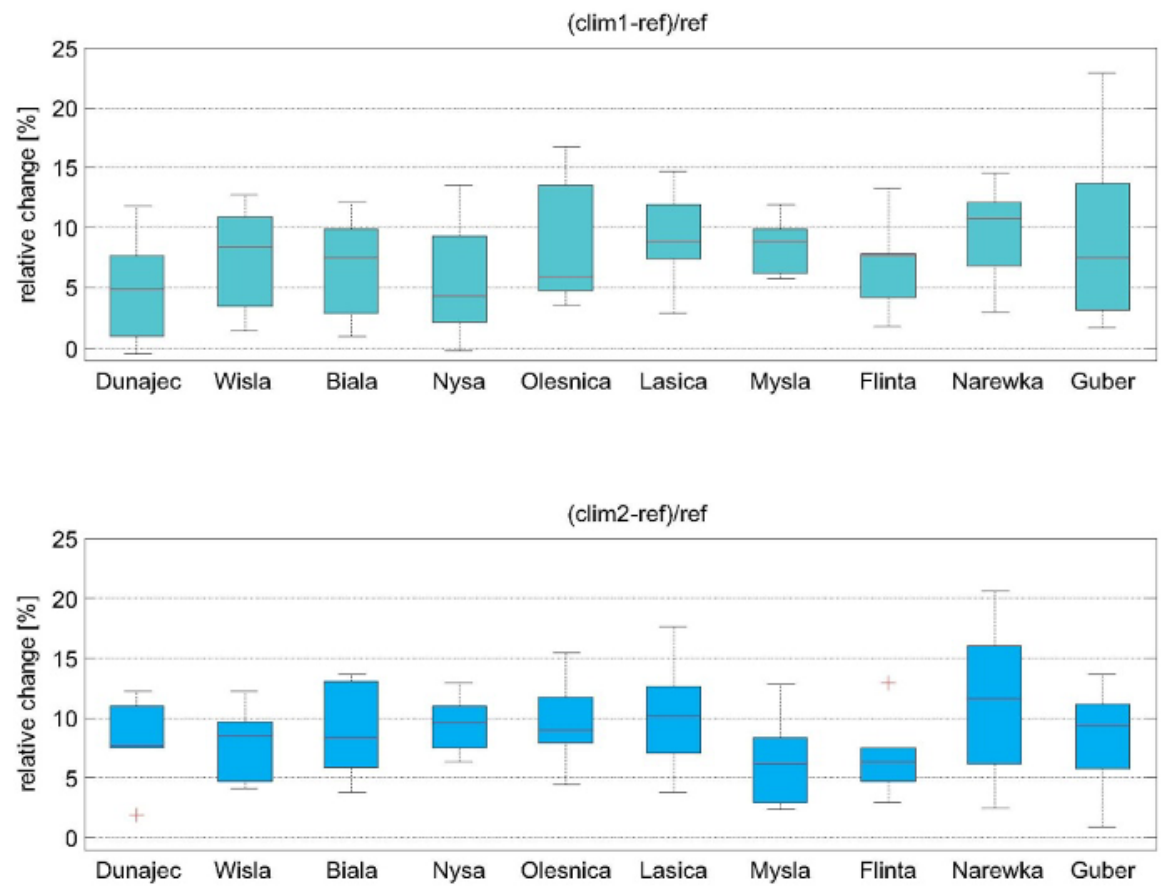

Fig. 6a. A comparison of the relative changes in annual precipitation totals in two future periods: 2021-2050 - upper panel, and 2071-2100 - lower panel versus reference period for Polish catchments. In each box, the central red mark denotes a median from seven climate model simulations, the edges of the box are the 25th and 75th percentiles, the whiskers extend to the most extreme data points not considered as outliers, and outliers are plotted individually in the form of red crosses. 

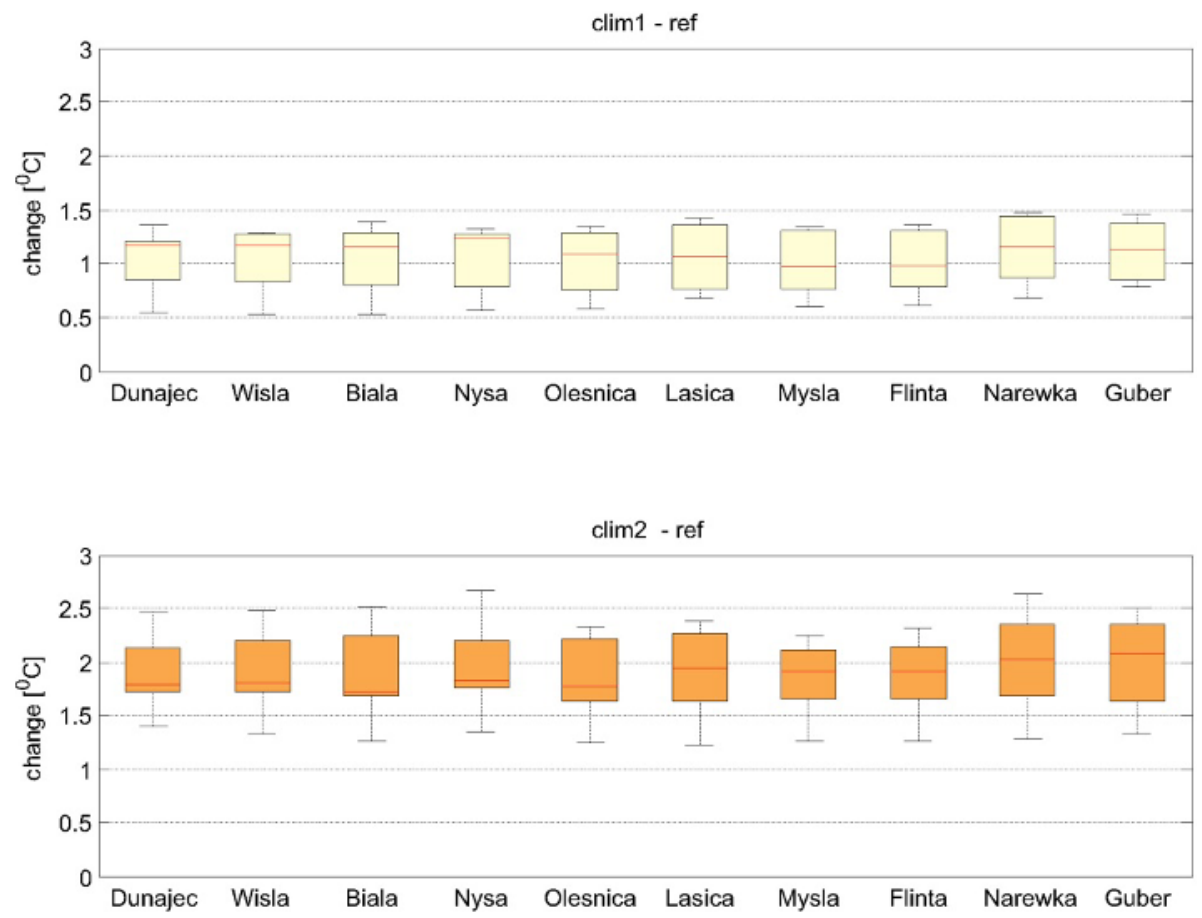

Fig. 6b. A comparison of the absolute changes in annual mean temperature $\left[{ }^{\circ} \mathrm{C}\right]$ in two future periods: 2021-2050 - upper panel, and 2071-2100 - lower panel versus reference period for Polish catchments. In each box, the central red mark denotes a median from seven climate model simulations, the edges of the box are the 25 th and 75th percentiles, the whiskers extend to the most extreme data points not considered as outliers, and outliers are plotted individually in the form of red crosses.

Figs. 6a and $\mathrm{b}$ for emission scenario RCP4.5. Relative changes in annual precipitation in two future periods as compared with the reference period are shown in Fig. 6a. The estimated tendency of changes depends on the analysed period and catchment. In the case of an annual change between the near future and the reference periods, the climate model simulations project an increase in the annual precipitation sums of less than $10 \%$ for all catchments for the near future, except Narewka. The tendency of changes between the far future and the reference periods is also similar for all catchments, but relative changes are larger than $10 \%$ for Lasica and Narewka catchments. A similar analysis was performed for changes in air temperature. In that case the results are presented in the form of absolute changes expressed in ${ }^{\circ} \mathrm{C}$ (Fig. 6b). In all cases, an increase in air temperature is projected but there are 
differences in the magnitude of the changes between catchments. An analysis of the tendency of changes in mean annual air temperature between the two future and the reference periods indicates an increase of about $1{ }^{\circ} \mathrm{C}$ for the near future (2021-2050) and $2^{\circ} \mathrm{C}$ for the far future (2071-2100) periods in comparison with the reference period 1971-2000.

A comparison of the change in annual precipitation and temperature in the two periods 2021-2050 and 2071-2100 relative to 1971-2000, for eight Norwegian catchments is presented in Figs. 7a (precipitation) and $7 \mathrm{~b}$ (temperature).

For the Norwegian catchments, changes in annual precipitation are positive, but smaller than for the Polish catchments. For the near-future, changes exceed $5 \%$ in 5 catchments (Eggedal, Futsavatn, Krinsvatn, Myglevatn, Polmak, Viksvatn), whilst in the far-future changes are over 10\% in Eggedal, Krinsvatn, and Polmak. The latter is the northernmost catchment in this study and is located north of the Arctic Circle. Interestingly, Polmak is also the catchment where the highest temperature changes occurred both in the near- and far-future.
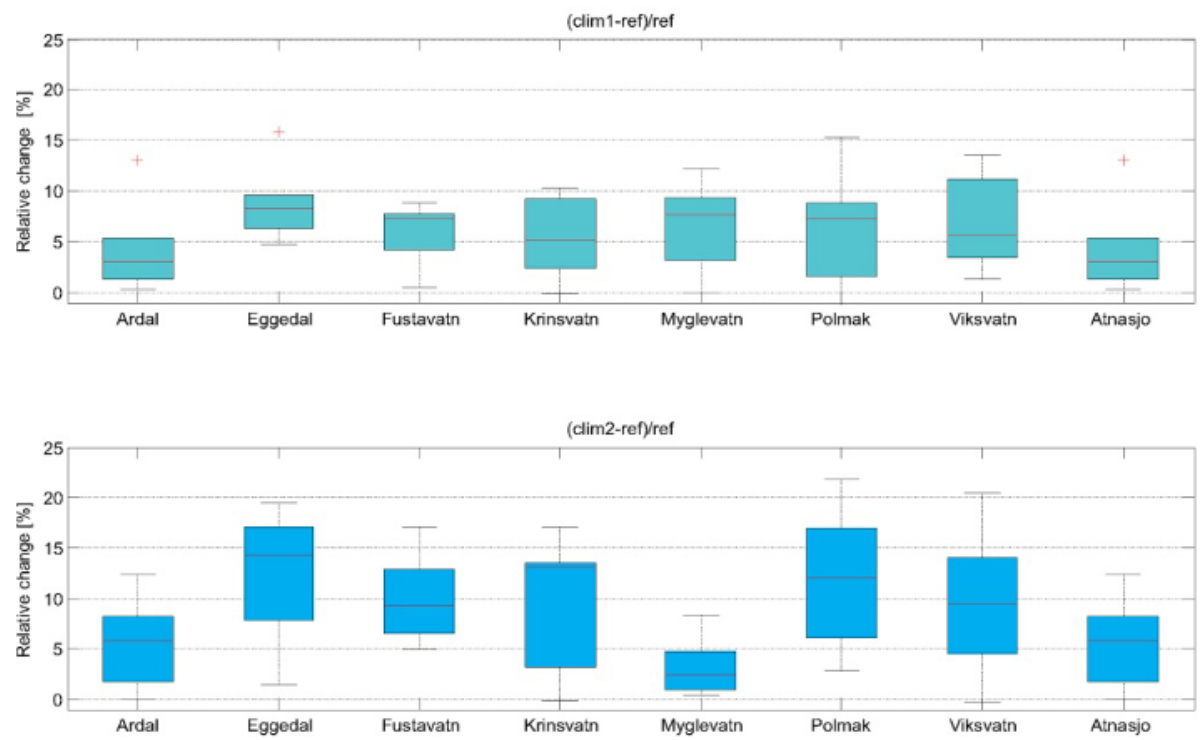

Fig. 7a. A comparison of the relative changes in the annual sum of precipitation in two future periods (2021-2050 and 2071-2100) versus the reference period for the Norwegian catchments. In each box, the central red mark denotes a median from seven climate model simulations, the edges of the box are the 25th and 75th percentiles, the whiskers extend to the most extreme data points not considered as outliers, and outliers are plotted individually in the form of red crosses. 

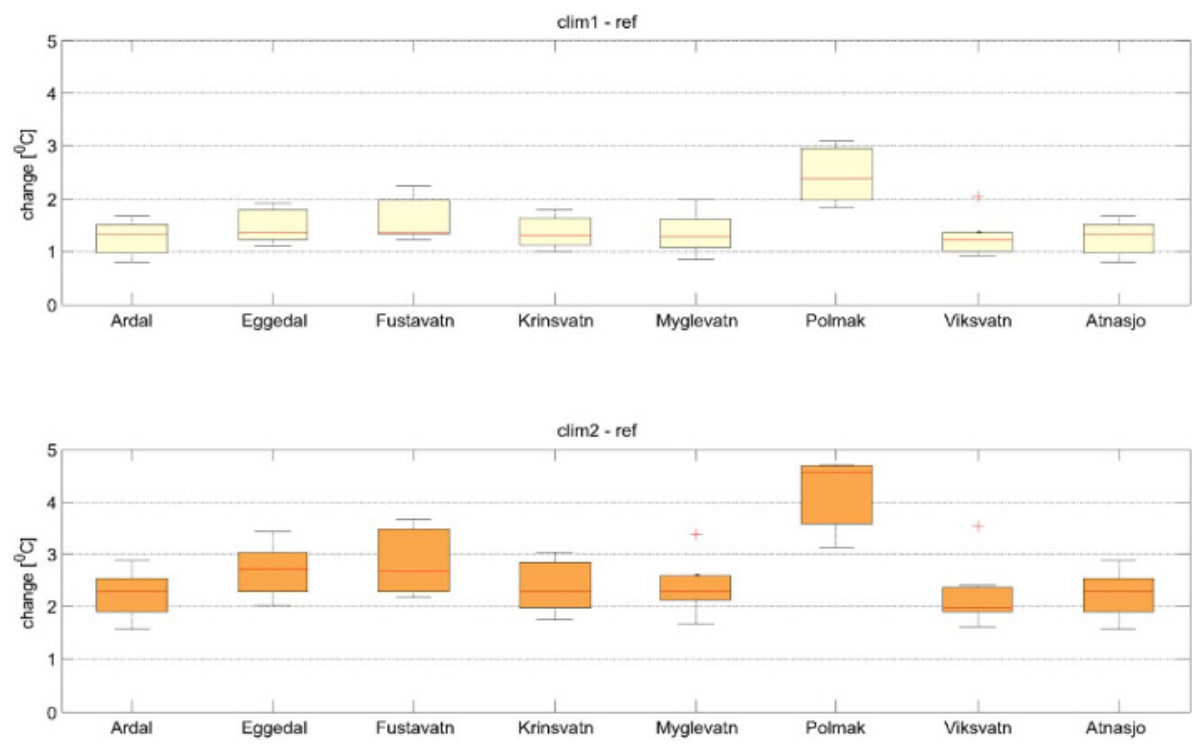

Fig. 7b. A comparison of the absolute changes in annual mean temperature $\left[{ }^{\circ} \mathrm{C}\right]$ in two future periods (2021-2050 and 2071-2100) versus the reference period for the Norwegian catchments. In each box, the central red mark denotes a median from seven climate model simulations, the edges of the box are the 25 th and 75 th percentiles, the whiskers extend to the most extreme data points not considered as outliers, and outliers are plotted individually in the form of red crosses.

\section{CONCLUSIONS}

This paper presents the background, objectives, and preliminary outcomes of the first year of activities of the project Climate Change Impact on Hydrological Extremes. Climate change affects temperature and precipitation, which act as driving forces for rainfall-runoff processes on a catchment scale. However, a catchment is affected not only by natural events, but also by human-induced changes. Therefore, in order to minimise other anthropogenic impacts on hydrological extremes, the choice of catchments for a climate impact study should follow well thought-through rules for catchment selection.

The methodology of catchment selection used here can be applied in similar studies. We list the main criteria that should be followed, of which the most important are the length of the observation series, their quality and homogeneity, the smallest number of human induced factors such as reservoirs, and river regulations. The degree of correlation between rainfall and catchment discharge measured by its modelling ability could also assist in the selection of catchments. Additional important criteria related to the na- 
ture of the project are the spatial locations of the catchments and their flood regimes. Based on these criteria, a project database was formed consisting of ten nearly-natural Polish and eight nearly-natural Norwegian catchments constructed for the purpose of climate impact assessment. This is the first study establishing a foundation for a Reference Hydrologic Networks (RHN) database in Poland.

As a climatic forcing indicator, we have used the newest source of climate projections available from the EURO-CORDEX initiative. An "intermediate pathway" RCP4.5 was presented in this paper, as an example of a medium high emission scenario. The RCP8.5 pathway is also being evaluated in the project. Seven RCM/GCMs were selected to provide daily projections of climatic variables up to the year 2100 at a resolution of $12.5 \mathrm{~km}$. The numerical tools were developed to efficiently handle those very large amounts of data that had to be downloaded and processed.

A comparison of simulations with observations in the reference period can be performed only by comparing distributions, as climate projections represent possible realisations of climate variables and not historical events. The comparison shows that those distributions differ, with larger discrepancies for precipitation than for temperature data. Two variants of the $Q M$ method were chosen to correct the biases in the RCM simulations. These were a theoretically-based double gamma function (Yang et al. 2010) for quantile mapping for precipitation and empirical quantile mapping for the residuals of air temperature.

A comparison of changes of projected temperature and precipitation series in two future periods was performed, a near-future period spanning from 2021-2050 and a far-future period 2071-2100. The results show increases in precipitation and temperature for the study catchments in both countries.

The results reaffirm the critical nature of the uncertainties involved in projections of future catchment meteorological forcing; these will have implications in the assessment of impact of climate changes on hydrological extremes.

Ongoing work in the project is evaluating low and high flow indices in the selected catchments, based both on observations and on projections to the end of the 21 st century. The analysis of trends of future changes in hydrological extremes will be incorporated into uncertainty and adaptation studies as outlined by Doroszkiewicz and Romanowicz (2014).

Acknowledgements. This work was partially supported by the project CHIHE (Climate Change Impact on Hydrological Extremes), carried out in the Institute of Geophysics, Polish Academy of Sciences, funded by Norway Grants (contract No. Pol-Nor/196243/80/2013), and partially supported 
within statutory activities No. 3841/E-41/S/2016 of the Ministry of Science and Higher Education of Poland. The hydro-meteorological data for Polish catchments were provided by the Institute of Meteorology and Water Management (IMGW), Poland.

\section{References}

Astrup, E. (2000), Homogeneity testing of hydrological data, NVE Rapport 7-2000, Norwegian Water Resources and Energy Directorate (NVE), Oslo, Norway (in Danish).

Beldring, S., T. Engen-Skaugen, E.J. Førland, and L.A. Roald (2008), Climate change impacts on hydrological processes in Norway based on two methods for transferring regional climate model results to meteorological station sites, Tellus A 60, 3, 439-450, DOI: 10.1111/j.1600-0870.2008. 00306.x.

Berg, P., H. Feldmann, and H.-J. Panitz (2012), Bias correction of high resolution regional climate model data, J. Hydrol. 448-449, 80-92, DOI: 10.1016/ j.jhydrol.2012.04.026.

Bergström, S., B. Carlsson, M. Gardelin, G. Lindström, A. Pettersson, and M. Rummukainen (2001), Climate change impacts on runoff in Sweden assessments by global climate models, dynamical downscaling and hydrological modelling, Clim. Res. 16, 101-112, DOI: 10.3354/cr016101.

Bergström, S., J. Andréasson, and L.P. Graham (2012), Climate adaptation of the Swedish guidelines for design floods for dams. In: Proc. 24th ICOLD Congress on Large Dams, 6-8 June 2012, Kyoto, Japan, Q94.

Cancelliere, A., and J.D. Salas (2004), Drought length properties for periodicstochastic hydrologic data, Water Resour. Res. 40, 2, W02503, DOI: 10.1029/2002WR001750.

Chung, C., and J.D. Salas (2000), Drought occurrence probabilities and risks of dependent hydrologic processes, J. Hydrol. Eng. 5, 3, 259-268, DOI: 10.1061/(ASCE)1084-0699(2000)5:3(259).

Clarke, L.E., J.A. Edmonds, H.D. Jacoby, H.M. Pitcher, J.M. Reilly, and R.G. Richels (2007), Scenarios of greenhouse gas emissions and atmospheric concentrations, Sub-report 2.1a, U.S. Climate Change Science Program. Synthesis and Assessment Product 2.1a, CCSP, Washington, $154 \mathrm{pp}$.

Cloke, H.L., F. Wetterhall, Y. He, J.E. Freer, and F. Pappenberger (2013), Modelling climate impact on floods with ensemble climate projections. Quart. J. Roy. Meteorol. Soc. 139, 671, 282-297, DOI: 10.1002/qj.1998.

Doroszkiewicz, J., and R. Romanowicz (2014), WP4 internal report on identifying flood management measures and constructions, overview of policy and law 
for adaptation process in Poland, Report CHIHE/WP4/I, IGP PAS, Warsaw, Poland.

Dyrrdal, A.V., K. Isaksen, H.O. Hygen, and N.K. Meyer (2012), Changes in meteorological variables that can trigger natural hazards in Norway, Clim. Res. 55, 2, 153-165, DOI: 10.3354/cr01125.

Edenhofer, O., B. Knopf, T. Barker, L. Baumstark, E. Bellevrat, B. Chateau, P. Criqui, M. Isaac, A. Kitous, S. Kypreos, M. Leimbach, K. Lessmann, B. Magné, S. Scrieciu, H. Turton, and D.P. van Vuuren (2010), The economics of low stabilization: model comparison of mitigation strategies and costs, The Energy J. 31, 1, 11-48, DOI: 10.5547/ISSN0195-6574-EJVol31-NoSI-2.

Edvardsen, S.-M., and C.M. Roald (2012), Flood zone map Naustdal, NVE Rapport 23/2012, Norwegian Water Resources and Energy Directorate (NVE), Oslo, Norway (in Norwegian).

EEA (2014), Corine Land Cover 2006 raster data, European Environment Agency, http://www.eea.europa.eu/data-and-maps/data/corine-land-cover-2006raster.

Favre, A.C., S. El Adlouni, L. Perreault, N. Thiémonge, and B. Bobée (2004), Multivariate hydrological frequency analysis using copulas, Water Resour. Res. 40, 1, W01101, DOI: 10.1029/2003WR002456.

Fernández, B., and J.D. Salas (1999a), Return period and risk of hydrologic events: I: Mathematical formulation, J. Hydrol. Eng. 4, 4, 297-307, DOI: 10.1061/ (ASCE)1084-0699(1999)4:4(297).

Fernández, B., and J.D. Salas (1999b), Return period and risk of hydrologic events: II. Applications, J. Hydrol. Eng. 4, 4, 308-316, DOI: 10.1061/(ASCE) 1084-0699(1999)4:4(308).

Fleig, A.K., L.M. Andreassen, E. Barfod, J. Haga, L.E. Haugen, H. Hisdal, K. Melvold, and T. Saloranta (2013) Norwegian Hydrological Reference Dataset for climate change studies, NVE Report 2-2013, Norwegian Water Resources and Energy Directorate (NVE), Oslo, Norway.

Gudmundsson, L., J.B. Bremnes, J.E. Haugen, and T. Engen-Skaugen (2012), Technical Note: Downscaling RCM precipitation to the station scale using statistical transformations - a comparison of methods, Hydrol. Earth Syst. Sci. 16, 3383-3390, DOI: 10.5194/hess-16-3383-2012.

Gustard, A., and S. Demuth (eds.) (2009), Manual on low-flow estimation and prediction, Operational Hydrology Report No. 50,WMO-No. 1029, World Meteorological Organization, Geneva, Switzerland.

Hannaford, J., and T. Marsh (2006), An assessment of trends in UK runoff and low flows using a network of undisturbed catchments, Int. J. Climatol. 26, 9, 1237-1253, DOI: 10.1002/joc.1303.

Hannaford, J., and T.J. Marsh (2008), High-flow and flood trends in a network of undisturbed catchments in the UK, Int. J. Climatol. 28, 10, 1325-1338, DOI: $10.1002 /$ joc. 1643 . 
Hannah, D.M., S. Demuth, H.A.J. van Lanen, U. Looser, C. Prudhomme, G. Rees, K. Stahl, and L.M. Tallaksen (2011), Large-scale river flow archives: importance, current status and future needs, Hydrol. Process. 25, 7, 11911200, DOI: 10.1002/hyp.7794.

Hisdal, H., and L.M. Tallaksen (2003), Estimation of regional meteorological and hydrological drought characteristics: a case study for Denmark, J. Hydrol. 281, 3, 230-247, DOI: 10.1016/S0022-1694(03)00233-6.

IOŚ-PIB (2013), Strategic adaptation plan for areas vulnerable for climate change 2020 prespective, Institute of Environmental Protection - National Research Institute (IOŚ-PIB), Warszawa, Poland (in Polish).

IPCC (2007), Climate Change 2007: Synthesis Report. Contribution of Working Groups I, II and III to the Fourth Assessment Report of the Intergovernmental Panel on Climate Change, Cambridge University Press, New York.

IPCC (2013), Climate Change 2013: The Physical Science Basis. Contribution of Working Group I to the Fifth Assessment Report of the Intergovernmental Panel on Climate Change, T.F. Stocker et al. (eds.), Cambridge University Press, New York, 1535 pp.

Jacob, D., J. Petersen, B. Eggert, A. Alias, O.B. Christensen, L.M. Bouwer, A. Braun, A. Colette, M. Déqué, G. Georgievski, E. Georgopoulou, A. Gobiet, L. Menut, G. Nikulin, A. Haensler, N. Hempelmann, C. Jones, K. Keuler, S. Kovats, N. Kröner, S. Kotlarski, A. Kriegsmann, E. Martin, E. van Meijgaard, C. Moselely, S. Pfeifer, S. Preuschmann, C. Radermacher, K. Radtke, D. Rechid, M. Rounsevell, P. Samuelsson, S. Somot, J.-F. Soussana, C. Teichmann, R. Valentini, R. Vautard, B. Weber, and P. Yiou (2014), EURO-CORDEX: new high-resolution climate change projections for European impact research, Reg. Environ. Change 14, 2, 563578, DOI: 10.1007/s10113-013-0499-2.

Kaczmarek, Z. (2003), The impact of climate variability on flood risk in Poland, Risk Anal. 23, 3, 559-566, DOI: 10.1111/1539-6924.00336.

Kaczmarek, Z., and J. Napiórkowski (1996), Water resources adaptation strategy in an uncertain environment. In: J.B. Smith, N. Bhatti, G.V. Menzhulin, R. Benioff, M. Campos, B. Jallow, F. Rijsberman, M.I. Budyko, and R.K. Dixon (eds.), Adapting to Climate Change, Springer, New York, 211224, DOI: 10.1007/978-1-4613-8471-7_18.

Kaczmarek, Z., J. Napiórkowski, and K.M. Strzepek (1996), Climate change impacts on the water supply system in the Warta river catchment, Poland, Int. J. Water Resour. Dev. 12, 2, 165-180, DOI: 10.1080/ 07900629650041939.

Kotlarski, S., K. Keuler, O.B. Christensen, A. Colette, M. Déqué, A. Gobiet, K. Goergen, D. Jacob, D. Lüthi, E. van Meijgaard, G. Nikulin, C. Schär, C. Teichmann, R. Vautard, K. Warrach-Sagi, and V. Wulfmeyer (2014), Regional climate modeling on European scales: a joint standard evaluation 
of the EURO-CORDEX RCM ensemble, Geosci. Model Dev. 7, 4, 12971333, DOI: $10.5194 /$ gmd-7-1297-2014.

Kriaučiūnienè, J., D. Meilutyte-Barauskienė, E. Rimkus, J. Kažys, and J. Vincevičius (2008), Climate change impact on hydrological processes in Lithuanian Nemunas river basin, Baltica 21, 1-2, 51-61.

Kundzewicz, Z.W., D. Graczyk, T. Mauer, I. Pińskwar, M. Radziejewski, C. Svensson, and M. Szwed (2005), Trend detection in river flow series: 1. Annual maximum flow, Hydrol. Sci. J. 50, 5, 797-810, DOI: 10.1623/ hysj.2005.50.5.797.

Kundzewicz, Z.W., I. Pińskwar, and G.R. Brakenridge (2013), Large floods in Europe, 1985-2009, Hydrol. Sci. J. 58, 1, 1-7, DOI: 10.1080/02626667. 2012.745082.

Lafon, T., S. Dadson, G. Buys, and C. Prudhomme (2013), Bias correction of daily precipitation simulated by a regional climate model: a comparison of methods, Int. J. Climatol. 33, 6, 1367-1381, DOI: 10.1002/joc.3518.

Lawrence, D., and I. Haddeland (2011), Uncertainty in hydrological modelling of climate change impacts in four Norwegian catchments, Hydrol. Res. 42, 6, 457-471, DOI: 10.2166/nh.2011.010.

Lawrence, D., and H. Hisdal (2011), Hydrological projections for floods in Norway under a future climate, NVE Report 5-2011, Norwegian Water Resources and Energy Directorate (NVE), Oslo, Norway.

Lawrence, D., I. Haddeland, and E. Langsholt (2009), Calibration of HBV hydrological models using PEST parameter estimation, NVE Report 1-2009, Norwegian Water Resources and Energy Directorate (NVE), Oslo, Norway, $44 \mathrm{pp}$.

Li, C.Z., L. Zhang, H. Wang, Y.Q. Zhang, F.L. Yu, and D.H. Yan (2012), The transferability of hydrological models under nonstationary climatic conditions, Hydrol. Earth Syst. Sci. 16, 1239-1254, DOI: 10.5194/hess-161239-2012.

Marsh, T. (2010), The UK Benchmark Network - designation, evolution and application. In: Fifth Int. Conf. on Water Resources and Environment Research, 5-7 July 2010, Quebec City, Canada.

Mishra, A.K., and P. Coulibaly (2010), Hydrometric network evaluation for Canadian watersheds, J. Hydrol. 380, 3-4, 420-437, DOI: 10.1016/j.jhydrol. 2009.11.015.

Mishra, A.K., and V.P. Singh (2011), Drought modeling - A review, J. Hydrol. 403, 1-2, 157-175, DOI: 10.1016/j.jhydrol.2011.03.049.

Monk, W.A., D.L. Peters, R.A. Curry, and D.J. Baird (2011), Quantifying trends in indicator hydroecological variables for regime-based groups of Canadian rivers, Hydrol. Process. 25, 19, 3086-3100, DOI: 10.1002/hyp.8137.

Moss, R.H., J.A. Edmonds, K.A. Hibbard, M.R. Manning, S.K. Rose, D.P. van Vuuren, T.R. Carter, S. Emori, M. Kainuma, T. Kram, G.A. Meehl, 
J.F.B. Mitchell, N. Nakicenovic, K. Riahi, S.J. Smith, R.J. Stouffer, A.M. Thomson, J.P. Weyant, and T.J. Wilbanks (2010), The next generation of scenarios for climate change research and assessment, Nature 463, 747-756, DOI: 10.1038/nature08823.

Nakicenovic, N., J. Alcamo, G. Davis, B. De Vries, J. Fenhann, S. Gaffin, K. Gregory, A. Grübler, T.Y. Jung, T. Kram, E.L. La Rovere, L. Michaelis, S. Mori, T. Morita, W. Pepper, H. Pitcher, L. Price, K. Raihi, A. Roehrl, H.-H. Rogner, A Sankovski, M. Schlesinger, P. Shukla, S. Smith, R. Swart, S. van Rooijen, N. Victor, and Z. Dadi (2000), Emissions Scenarios. A Special Report of Working Group III of the Intergovernmental Panel on Climate Change, Cambridge University Press, Cambridge, 599 pp.

Nash, J.E., and J.V. Sutcliffe (1970), River flow forecasting through conceptual models. Part I - A discussion of principles, J. Hydrol. 10, 3, 282-290, DOI: 10.1016/0022-1694(70)90255-6.

Osuch, M., J. Kindler, R.J. Romanowicz, K. Berbeka, and A. Banrowska (2012), Strategia adaptacji Polski do zmian klimatu w zakresie sektora "Zasoby i gospodarka wodna", KLIMADA Project, Institute of Environmental Protection, National Research Institute, Warsaw, Poland (in Polish).

Osuch, M., R.J. Romanowicz, D. Lawrence, and W.K. Wong (2015), Assessment of the influence of bias correction on meteorological drought projections for Poland, Hydrol. Earth Syst. Sci. Discuss. 12, 10331-10377, DOI: 10.5194/ hessd-12-10331-2015.

Piani, C., J.O. Haerter, and E. Coppola (2010), Statistical bias correction for daily precipitation in regional climate models over Europe, Theor. Appl. Climatol. 99, 1, 187-192, DOI: 10.1007/s00704-009-0134-9.

Raje, D., and P.P. Mujumdar (2010), Reservoir performance under uncertainty in hydrologic impacts of climate change, Adv. Water Resour. 33, 3, 312-326, DOI: 10.1016/j.advwatres.2009.12.008.

Reitan, T., and A. Petersen-Øverleir (2005), Evaluating the homogeneity of hydrological time series with the help of Bayesian regression, NVE Report 5-2005, Norwegian Water Resources and Energy Directorate (NVE), Oslo, Norway (in Norwegian).

Romanowicz, R.J., and M. Osuch (2011), Assessment of land use and water management induced changes in flow regime of the Upper Narew, Phys. Chem. Earth 36, 13, 662-672, DOI: 10.1016/j.pce.2011.04.012.

Romanowicz, R.J., M. Osuch, and M. Grabowiecka (2013), On the choice of calibration periods and objective functions: A practical guide to model parameter identification, Acta Geophys. 61, 6, 1477-1503, DOI: 10.2478/ s11600-013-0157-6.

Sadowski, M. (2008), An approach to adaptation to climate changes in Poland, Climate Change 90, 4, 443-451, DOI: 10.1007/s10584-008-9394-0. 
Salvadori, G., and C. De Michele (2004), Frequency analysis via copulas: Theoretical aspects and applications to hydrological events, Water Resour. Res. 40, 12, W12511, DOI: 10.1029/2004WR003133.

Shiau, J., and H. Shen (2001), Recurrence analysis of hydrologic droughts of differing severity, J. Water Resour. Plan. Manage 127, 1, 30-40, DOI: 10.1061/(ASCE)0733-9496(2001)127:1(30).

Slack, J.R., and J.M. Landwehr (1992), Hydro-climatic data network (HCDN); A U.S. Geological Survey streamflow data set for the United States for the study of climatic variations, 1874-1988, Open-file Report 92-129, U. S. Geol. Survey, Reston, USA.

Sorteberg, A., I. Haddeland, J.E. Haugen, S. Sobolowski, and W.K. Wong (2014), Evaluation of distribution mapping based bias correction methods, Norwegian Centre for Climate Services, NCCS Report 1/2014, 23 pp.

Stahl, K., H. Hisdal, J. Hannaford, L.M. Tallaksen, H.A.J. van Lanen, E. Sauquet, S. Demuth, M. Fendekova, and J. Jódar (2010), Streamflow trends in Europe: evidence from a dataset of near-natural catchments, Hydrol. Earth Syst. Sci. 14, 2367-2382, DOI: 10.5194/hess-14-2367-2010.

Storn, R., and K. Price (1997), Differential evolution - a simple and efficient heuristic for global optimization over continuous spaces, J. Global Optim. 11, 4, 341-359, DOI: 10.1023/A:1008202821328.

Strupczewski, W.G., K. Kochanek, E. Bogdanowicz, W. Feluch, and I. Markiewicz (2012), A Two-Level Method of Estimation of Non-stationary Flood Quantiles, Monografie Komitetu Gospodarki Wodnej PAN, Warszawa, No. 35, 109-124 (in Polish).

Strupczewski, W.G., E. Bogdanowicz, and S. Debele (2015), The estimation of trends in quantiles by means of selected pdf fitted to seasonal, annual or partial duration (named also Peaks Over Threshold - POT) flow series, Report CHIHE/WP3/I, IGP PAS, Warsaw, Poland.

Teng, J., J. Vaze, F.H.S. Chiew, B. Wang, and J.-M. Perraud (2012), Estimating the relative uncertainties sourced from GCMs and hydrological models in modeling climate change impact on runoff, J. Hydrometeorol. 13, 1, 122139, DOI: 10.1175/JHM-D-11-058.1.

Thorne, J.H., R. Boynton, L. Flint, A. Flint, and T.-N. Le (2010), Development and application of downscaled hydroclimatic predictor variables for use in climate vulnerability and assessment studies, Publication No. CEC-5002012-010, California Energy Commission, Davis, USA.

Tveito, O.E., I. Bjørdal, A.O. Skjelvåg, and B. Aune (2005), A GIS-based agroecological decision system based on gridded climatology, Meteorol. Appl. 12, 1, 57-68, DOI: $10.1017 / \mathrm{S} 1350482705001490$.

van der Linden, P., and J.F.B. Mitchell (2009), ENSEMBLES: climate change and its impacts: summary of research and results from the ENSEMBLES project, Met Office Hadley Centre, Exeter, UK. 
van Vuuren, D.P., P.L. Lucas, and H. Hilderink (2007), Downscaling drivers of global environmental change: Enabling use of global SRES scenarios at the national and grid levels, Global Environ. Change 17, 1, 114-130, DOI: 10.1016/j.gloenvcha.2006.04.004.

Veijalainen, N., E. Lotsari, P. Alho, B. Vehviläinen, and J. Käyhkö (2010), National scale assessment of climate change impacts on flooding in Finland, J. Hydrol. 391, 3-4, 333-350, DOI: 10.1016/j.jhydrol.2010.07.035.

Whitfield, P.H., D.H. Burn, J. Hannaford, H. Higgins, G.A. Hodgkins, T. Marsh, and U. Looser (2012), Reference hydrologic networks I. The status and potential future directions of national reference hydrologic networks for detecting trends, Hydrol. Sci. J. 57, 8, 1562-1579, DOI: 10.1080/02626667. 2012.728706.

Wilson, D., H. Hisdal, and D. Lawrence (2010), Has streamflow changed in the Nordic countries? - Recent trends and comparisons to hydrological projections, J. Hydrol. 394, 3-4, 334-346, DOI: 0.1016/j.jhydrol.2010. 09.010 .

Wong, W.K., S. Beldring, T. Engen-Skaugen, I. Haddeland, and H. Hisdal (2011), Climate change effects on spatiotemporal patterns of hydroclimatological summer droughts in Norway, J. Hydrometeorol. 12, 6, 1205-1220, DOI: 10.1175/2011JHM1357.1.

Yang, W., J. Andréasson, L.P. Graham, J. Olsson, J. Rosberg, and F. Wetterhall (2010), Distribution-based scaling to improve usability of regional climate model projections for hydrological climate change impacts studies, Hydrol. Res. 41, 3-4, 211-229, DOI: 10.2166/nh.2010.004.

Received 26 January 2016

Received in revised form 29 February, 2016

Accepted 4 March 2016 